\title{
College integration and social class
}

\author{
María José Álvarez-Rivadulla ${ }^{1} \cdot$ Ana María Jaramillo ${ }^{2,3} \cdot$ Felipe Fajardo $^{4} \cdot$ Laura Cely $^{1}$. \\ Andrés Molano $^{5} \cdot$ Felipe Montes $^{2}$
}

Accepted: 16 November 2021 / Published online: 24 January 2022

(C) The Author(s), under exclusive licence to Springer Nature B.V. 2021

\begin{abstract}
What is the impact of social class on college integration? Higher education institutions are becoming more diverse, yet the integration of underprivileged students remains a challenge. Using a social network approach, we analyze the general integration of low socioeconomic status (SES) students, as well as how segregated by class these friends are. The object of analysis is the extreme case of an elite university that, based on a government loan program (Ser Pilo Paga), opened its doors to many low-SES students in a very unequal country, Colombia. Using a mixed methods perspective, including a survey, 61 in depth interviews, and ethnographic observation, we analyze friendship networks and their meanings, barriers, and facilitators. Contrary to the literature, we find that low-SES students had, on average, the same number of connections and were no more isolated than students from upper social classes. Also, low-SES students' networks were not more segregated, even if relations with the upper classes were less likely and required more relational work than with middle or lower class friends. This high level of social integration stemmed from the intense relational work that low-SES students engage in, so as to fit in. Middle class friends act as a catalyst that can enable cross-class friendships.
\end{abstract}

Keywords College integration · Friendship networks · Inter-class relations · Segregation · Social class $\cdot$ Ser Pilo Paga $\cdot$ Colombia

\section{Introduction}

Higher education institutions are becoming more diverse across the globe, partly due to massification and partly due to deliberate attempts to include minorities, particularly in elite institutions which have remained the least diverse. Looking at diversity beyond enrollment (Park et al., 2019) is crucial in terms of understanding its consequences and improving its outcomes for both institutions and individuals. Lower-class students tend to be less socially integrated in college than middle-class students (Rubin, 2012). Lower levels of integration, in turn, have a negative effect on their persistence, performance, and subjective well-being (Ostrove \& Long, 2007; Robbins et al., 2004; Rubin et al., 2016). This study addresses the question of the extent to which low socioeconomic status (SES) students in

María José Álvarez-Rivadulla

mj.alvarez@uniandes.edu.co

Extended author information available on the last page of the article 
an elite college, in an extremely unequal context are segregated or integrated, by exploring their social ties. We analyze low socioeconomic status (SES) students' general integration — how many friends they have — and how segregated by class these friends are, as well as the meanings, barriers, and facilitators of these networks. ${ }^{1}$ We do so by using a mixed method perspective, including a network survey, 61 in-depth interviews, and ethnographic observations.

Having different social classes in the same institution increases - but does not guarantee - the probability of cross-class interaction. Non-segregated class ties can be particularly helpful to the most underprivileged students (Rubin, 2012). Befriending students with a higher SES may help low-SES students acquire taken-for-granted knowledge in the college environment (Jack, 2016a), or to capitalize on their previous knowledge to thrive socially and academically (Rios-Aguilar et al., 2011). By connecting with higher SES students, low-SES students might improve their academic performance (Agurto Adrianzén et al., 2019), and increase their chances of accessing better jobs in the future (Granovetter, 1977). Yet, these non-segregated ties can also be helpful to the most privileged students who may also increase their performance (Agurto Adrianzén et al., 2019) or become more prosocial due to these diverse interactions (Rao, 2019). Diverse networks can also lead to positive community outcomes fostering a better learning environment for everyone (Hurtado et al., 1998; Park et al., 2013).

Most research about social integration of underprivileged students in college has been conducted in high-income countries with varying but not excruciating levels of inequality. In this article, we analyze an extreme case. We study an elite institution in Colombia, a middle-income country with enormous income and educational gaps. A governmentfinanced program - Ser Pilo Paga (SPP) - enabled many low-SES students to access higher education, including private institutions with fees that they would be very hard pressed to afford. The SPP program allocated 10,000 forgivable loans per year during its 4-year duration (2015-2018), dramatically increasing the structural class diversity of many higher education institutions, including the one in our case study. The students that we found together in a classroom would have never met otherwise. They belonged to different segregated worlds in which they lived apart, attended different schools, and socialized in different spaces. Hence, this program offered a unique opportunity to observe unprecedented cross-class interactions.

Contrary to the literature that highlights their lower social integration, we found that low-SES students were no more isolated in their networks than upper social class students, nor were their friendship networks more segregated. However, according to our qualitative data, relations with upper-class students were less likely and required more relational work than those with middle-class classmates due to higher economic and cultural capital barriers. Methodologically, our work highlights that friendship network measures hide the intense integration burden that low-SES had to assume to be able to camouflage themselves and therefore fit in. This work has at least two different implications. On the one hand, it emphasizes the crucial role of the middle classes in college integration. Their presence facilitates underprivileged students' integration to elite environments. On the other hand, it can help institutions think about what they are doing to alleviate the invisible burden that

\footnotetext{
${ }^{1}$ We use SES and class interchangeably to make the text more readable, even if we understand the terms belong to different sociological traditions. Later in the text, we explain how we separated students in three different SES levels or classes.
} 
less privileged students face when entering college and, therefore, engage with their integration beyond enrollment.

\section{Social integration and the underprivileged in higher education}

Promoting access to high-quality higher education for a diversified population is crucial in terms of establishing more equal societies. Higher education can serve as an important vehicle for social mobility, although this greatly depends on how much the context provides access, retention, and labor opportunities for graduates of dissimilar origins (Billingham, 2018). Although there are still huge gaps, especially if consider institutional quality, access to higher education has indeed become more diversified worldwide (Marginson, 2016). Even elite colleges are opening their doors to more assorted populations, through affirmative action policies, scholarships, loans, or other types of national, local, or institutional policies. Specifically, in Latin America, the number of students in higher education programs has nearly doubled since 2000, and access has become more equitable (Ferreyra et al., 2017). Understanding what happens with lower-class students after they enter universities becomes crucial to improving their experience, ensuring retention, and promoting social mobility.

Social integration is decisive for students' performance and wellbeing in college, and, according to the literature, lower-class students are usually less integrated (Rubin, 2012; Rubin \& Wright, 2015). Research shows that lower-class students interact less with peers and professors and have more difficulties in navigating the institutional environment than their upper-class peers. However, this varies depending on their previous experiences, especially their high school experience (Jack, 2016b, 2019), and the specific cultural and aspirational context (Xie \& Reay, 2019). Differences in their cultural and social capital (Bourdieu, 1998; Lareau, 2015) underlie their feelings of inadequacy and isolation, as the educational environment places different values on the forms of cultural and social capital habitual to upper-class students with respect to the different knowledge, skills, and resources that lower-class students bring with them to university, and, in turn, also rewards them differentially (Rios-Aguilar et al., 2011). Their integration becomes even harder in elite institutions where students feel more excluded and estranged (Aries \& Seider, 2005; Aries, 2008; Reay et al., 2009; Elizabeth M Lee \& Kramer, 2013; Corredor et al., 2020). Social integration, in turn, plays a pivotal role for college students' persistence, performance, and subjective wellbeing (Ostrove \& Long, 2007; Rubin et al., 2016). To help social integration, universities should create safe non-segregated spaces in which to discuss background differences, and thus, diminish misconceptions about other socio-economical classes, and ensure the wellbeing of new underrepresented students (Hurtado et al., 1998).

\section{Integration in college from a network perspective}

Social integration in higher education is often measured at individual level. In his revealing meta-analysis of studies that evaluate the impact of class on social integration in college, Rubin (2012) defines integration as "the quantity and quality of social interactions that students have with faculty and other students" (p. 22). There are several ways of measuring this, from subjective belonging to the institutions, to self-reporting of college engagement in formal and informal activities. Although working-class students report lower levels of integration than students in higher socioeconomic classes in most of the studies reviewed, different measures vary in their ability to detect social 
class effects. Hence, Rubin recommends using multiple measures. Although not present in that review, other authors advocate for measuring integration using social networks.

Looking at integration as networks has a long tradition in sociology and dates back to one of its founders, Emile Durkheim, and his perspective on solidarity as social ties. Recovering this tradition, Thomas (2000) proposes centrality measures as de facto measures of structural integration in higher education, with those more central to a network being more integrated into it. Following up on this perspective, Smith (2015) uses centrality measures to divide students between "magnets" (high indegree) and "seekers" (high outdegree) of academic help. She finds that grade point average (GPA) is crucial for magnets, especially when the environment makes it possible for others to know who has a high GPA (when they belong to an intervention dubbed a "learning community").

Centrality or the degree to which an individual is more or less connected in a network is a crucial dimension of integration, that we here call general integration. Yet, besides the sheer number of social ties, understanding integration from a network perspective enables us to measure the second dimension. That is, how diverse or segregated (homophilic) the networks that students build in college are (Bojanowski \& Corten, 2014).

For lower-class students, befriending students from higher socioeconomic classes is a crucial dimension, often overlooked by the literature. In traditional and elite institutions, upper-class students can act as "cultural guides" (Lareau, 2015) to the lower-class students, helping them to understand the explicit and implicit college knowledge and, more generally, the middle- or upper-class cultural capital they do not bring from home which is overwhelmingly assumed by higher education institutions to be the norm (Stephens et al., 2012). Cultural capital is a symbolic form of distinction based on acquired academic knowledge, language mastering, tastes, manners, and ways of carrying oneself and relating to others (Bourdieu [1986] 2011, 1984). What education institutions, especially elite ones, consider to be a good or even a "normal" student is often covertly related to middle- and higher-class values and manners, for example, in our context, speaking up in class showing entitlement but never being confrontational. In contrast, working-class culture is constructed as deficient (Ingram, 2011). Since what needs to be learned is never made explicit and is often full of complexities and subtleties, it can be useful for lower-class students to have friends from higher socioeconomic classes who can act as "cultural guides."

Moreover, as expressed in the introduction, cross-class relationships may increase lowSES students' chances of improving their academic performance and getting better jobs in the future. The literature on social capital - that is the quality and quantity of resources an actor has depending on her position in a social network (Lin, 2000) - has proved this for different contexts. Ties matter and so do the resources - such as information or opportunities - attached to them, especially in the labor market. We can call this dimension of integration cross-class or, even more generally, cross-group integration.

The literature on diversity in higher education institutions from a social networks perspective, tends to find highly segregated networks. With most of it being based on the USA, this literature emphasizes the role of race and racism in structuring social networks. Yet, interesting intersections appear between race and class. Inter-racial friendships are more likely among individuals that are closer in terms of their socioeconomic class (Park et al., 2013, 2019), whereas class differences can inhibit same-race friendships (Torres \& Massey, 2012). This resonates with the role of cultural capital in friend-making. Shared cultural capital facilitates interactions between different social groups. What might seem like a simple taste or personality differences that incline individuals towards some and not others, often hides social class inequalities. 
We tend to befriend those that are similar to us. Social networks tend to be homophilic (McPherson et al., 2001). Hence, class homophily in college comes as no surprise when neighborhoods and school segregation are the norm. Yet, organizational environments may abate this homophilic trend. For example, more structural diversity can foster less homophilic interactions (Park et al., 2019). It is now an old tested hypothesis that more contact breeds less inter-group prejudice (Allport, 1954; Pettigrew et al., 2011), and thus could imply less homophily. Moreover, as found by Lee (2016) in her illuminating ethnography of class and college life, even in elite institutions with little, yet some, diversity, inter-class friendships may happen because of shared experiences and spaces, ambiguities in figuring out class, and institutional and interpersonal class silences.

\section{The case}

\section{Inequality and higher education in Colombia}

With a Gini index of 0.497 (World Bank 2017), Colombia is the seventh most unequal country in the world. Although recent years have witnessed a considerable decrease in poverty and a much more modest reduction in inequality, the COVID-19 pandemic has dramatically increased poverty (to $42.5 \%$ of the population according to the National Statistics Department DANE) and probably inequality as well (data still not available). As evinced by their cities and school systems, Latin American societies are deeply unequal, fragmented, and segregated. Bayon (2015) states that, to understand contemporary Latin American societies that have extended their services to the poor, it is crucial to think, not only in terms of exclusion but also, and fundamentally, of exclusionary integration. The poor can now access more years of education, but quality gaps are still enormous (Ferreyra et al., 2017). For the Colombian case, and considering only higher education, the coverage rate has grown significantly in recent years, reaching 52\% of 17- to 21-year-olds (SNIES, 2018). This increase corresponds to the rise in primary and secondary education. It has led to a proliferation of higher education institutions that by 2014 added up to 288 among technical schools, universities, and technological institutions (Melo et al., 2014).

In Colombia, all students graduating from high school must present the state exam (Saber 11) to be admitted to higher education institutions. In a context of deep family inequality and a highly unequal and class-segregated primary and secondary educational system (García et al., 2015; García-Villegas \& López, 2011), students' SES greatly determines both their results in the state exam and, in turn, their access to higher education, not to mention to high quality institutions. The higher education system is, in turn, heavily stratified. In the first place, high-quality private institutions are mainly accessible only to middle- and high-SES families given the expensive tuition fees. Secondly, there are public institutions of heterogeneous quality and social composition, with more accessible tuition costs for middle-to-low-SES families but with limited coverage due to insufficient government funding and requiring very competitive admission exams, in addition to the Saber 11. Hence, those public institutions are often out of reach for lower-income students who have relatively poor quality primary and secondary education (Gómez Campo \& Celis Giraldo, 2009). Finally, there are low-quality private institutions that some low-SES students can afford to access both financially and academically, although with dubious returns in the labor market (González-Velosa et al., 2015). This tends to reinforce the poverty cycles for those low-SES students. 


\section{The Ser Pilo Paga program}

In an attempt to change this educational context for a group of exceptional underprivileged students that, despite their hardships, managed to perform outstandingly in the Saber 11 test, the Colombian government implemented a policy intervention dubbed Ser Pilo Paga (SPP) or Being Smart Pays, which ran between 2014 and 2018. For 4 years, 10,000 beneficiaries received a demand-based subsidy to enter the accredited higher education institution of their choice, for the duration of their studies. The subsidy included tuition fees and a stipend and was forgivable provided the student graduated. To qualify, students had to fulfill three requirements. First, they needed an exceptionally high score in the Saber 11 (top decile); second, their household needed to be categorized as extremely poor according to a state survey used to target social policy (SISBEN); and, finally, they had to be admitted by the program they applied to at an accredited higher education institution (Medina et al., 2018). According to the first program evaluations, a year later (in 2016), the chance for eligible youngsters to access high-quality higher education institutions had increased by 46.5 percentage points (426.6\%) (Londoño-Vélez et al., 2020). Most students chose private universities, mainly because of the institutions' perceived prestige or because they did not pass the entrance exam for public institutions.

The SPP program disrupted the existing segmentation in access to higher education, especially in elite private universities where, for the first time, a high proportion of students were not from the most privileged classes. In our case study, an elite private institution (henceforth Study University), the impact of this program on the class composition of its students was massive and unprecedented. While the proportion of low-SES students was less than $5 \%$ before SPP, it rose to about $30 \%$ of the incoming cohorts while the program lasted. ${ }^{2}$ Thus, the program constitutes an opportunity to observe possible interclass network formation and especially how lower-class students integrate into those networks.

\section{A note of race in higher education in Colombia and Latin America}

Although this study focuses on class, a note on race is crucial, especially because the scholarship on school integration and diversity in the USA focuses on racial disparities. Latin American societies are deeply "pigmentocratic" (Telles, 2014), and Colombia is no exception (Urrea et al., 2014). Having darker skin limits opportunities and social mobility (Viáfara López, 2017). A long history of colonization, slavery, and continuous institutional and everyday racism is behind current disparities in the educational attainment of indigenous and blacks in the region and in this country in particular. It is precisely because of these deep inequalities that the scholarship students were of lighter skin than economically similar populations (Alvarez-Rivadulla 2017). Those that were able to excel in their state exams despite being poor were not, on average, the darkest-skinned students in the country. Although Study University does not collect data on ethnicity and race, the presence of Afro or indigenous students is notably low.

\footnotetext{
${ }^{2}$ Percentages are for students from socioeconomic strata 1 and 2 according to Colombian official statistics comparing the composition of the 2013 and 2014 incoming semesters with the first semester of the program in 2015 and its second cohort in 2016.
} 


\section{Data and methods}

This study was conducted over 4 years (2016-2020) at an elite higher education institution in Colombia. ${ }^{3}$ The research design had a mixed methods approach, mixing qualitative and quantitative techniques, and also including both perspectives throughout the research process, from the questions, to data collection, analysis, and the interpretation of findings (Creswell \& Tashakkori, 2007; Tashakkori \& Teddlie, 2008). Some parts were sequential, while others were concurrent. A network survey was designed after the first pilot qualitative interviews. Following the survey, two batches of interviews were conducted. About half of the interviews (34) were based on the survey results. The interviewees were selected sequentially to maximize variation in students' demographics and social integration measured through friendship networks. The same questionnaire was used for the remaining half of the interviews (28), but the sampling for these was less structured, although the researchers sought to maintain variation, including outliers, a sampling strategy more often used in ethnographic research. The interviewees were selected in the context of participant observation or snowball sampling, and some through specific searches because of certain characteristic (e.g., being part of a scholarship students' group). Ethnographic observations helped to investigate the institution's culture and how it dealt with diversity. While the quantitative data allowed us to capture social relationships and implement social network analysis formally, the qualitative data provided us with an in-depth understanding of the content of the networks, their meanings, and the experiences of students embedded in them, hence actualizing the methodological contribution of the paper.

\section{Quantitative data collection}

We collected individual and relational data in an online survey distributed through the institutional e-mail. Participants were students who started their undergraduate studies in January 2017. Responses were voluntary, and as an incentive, we raffled gift cards for a popular burger restaurant. Students completed the survey between November and December of 2018, when they were at the end of their second year at the Study University. Surveys included questions on social networks, where students had to indicate whether they considered each of their program classmates as friends (we gave them the list of names). From these data, we associated each nomination with a relationship. We use these networks to analyze students' social integration in the university. Although this method does not provide the possibility to map all the possible friendships a student can have in the university, we based our choice on certain theoretical and practical reasons. First, it reveals the complete structure of a specific and very important type of network: friendship among same program classmates which can be crucial in terms of social integration in college and future opportunities in the job market. Classmates may not be the only friends students make, but they cannot elude this type of interaction in the classroom. Second, having a delimited sample allowed us to access and control other variables that could mediate integration inside the program from administrative sources, e.g., GPA. Finally, bounded networks enabled us to analyze the existence or absence and the direction of relationships (Newman, 2010).

\footnotetext{
3 We also included five interviews in two other private universities and a public university with students on the SPP program, as an exploratory exercise of comparison with other contexts.
} 
Table 1 Survey respondents' demographics in comparison to their cohorts

\begin{tabular}{|c|c|c|c|c|}
\hline & \multicolumn{2}{|c|}{ Respondents } & \multicolumn{2}{|c|}{2017 Cohort } \\
\hline & $N$ & $\%$ & $N$ & $\%$ \\
\hline \multicolumn{5}{|l|}{ Program } \\
\hline Program 1 & 51 & 34.23 & 76 & 31.15 \\
\hline Program 2 & 38 & 25.50 & 70 & 28.69 \\
\hline Program 3 & 36 & 24.16 & 56 & 22.95 \\
\hline Program 4 & 24 & 16.11 & 42 & 17.21 \\
\hline Total & 149 & 100.00 & 244 & 100.00 \\
\hline \multicolumn{5}{|l|}{ Sex distribution } \\
\hline Male & 90 & 60.40 & 148 & 60.66 \\
\hline Female & 59 & 39.60 & 93 & 38.11 \\
\hline Total & 149 & 100.00 & 241 & 98.77 \\
\hline \multicolumn{5}{|l|}{ Scholarship status distribution } \\
\hline Ser Pilo Paga scholarship holder & 93 & 62.42 & 143 & 58.61 \\
\hline Non-Ser Pilo Paga scholarship holder & 56 & 37.58 & 92 & 37.70 \\
\hline Total & 149 & 100.00 & 235 & 96.31 \\
\hline \multicolumn{5}{|l|}{ SES distribution } \\
\hline Low-SES & 58 & $38.93 \%$ & 98 & $40.16 \%$ \\
\hline Middle-SES & 52 & $34.90 \%$ & 73 & $29.92 \%$ \\
\hline High-SES & 38 & $25.50 \%$ & 61 & $25.00 \%$ \\
\hline \multirow[t]{2}{*}{ Total } & 148 & $99.33 \%$ & 232 & $95.08 \%$ \\
\hline & Mean & Std. dev & Mean & Std. dev \\
\hline 2018-2 GPA (mean) & 3.87 & 0.35 & 3.78 & 0.44 \\
\hline Total & 149 & & 244 & \\
\hline Total & $N=$ & 149 & $N=$ & 244 \\
\hline
\end{tabular}

Surveys were applied in four different programs - unnamed for reasons of confidentiality - belonging to very different knowledge areas, from health to engineering to the social sciences. We wanted to maximize variation in program cultures to be sure that the patterns we found were not a byproduct of some program idiosyncrasy. We chose these programs because they had a medium-sized number of incoming students but differed in their socioeconomic composition. The programs vary in their proportions of low, middle-, and upper-class students, offering an interesting variation in terms of structural opportunities for interaction across social classes (Neal, 2010).

One hundred and forty-nine (149) students completed the survey. Students who did not complete the entire survey were not excluded from the analysis because we have information about them via administrative data and the nominations they received in the relational data. We compared those that answered the survey with their entire cohorts in some variables looking for problematic trimming or biases in our sample and found none. Respondents represented their cohorts in their sex, scholarship status, GPA, and SES (Table 1).

Authors' data set mixing data from the freshman survey conducted by the Study University over induction and administrative data also from the university.

To divide students into three groups, low, middle, and upper-SES, we used the Colombian official population division into six socioeconomic strata, based on current residence 
and highly correlated with education and income, but we mixed that criteria with scholarship status. Based on these two socioeconomic measures, we divided our students into three groups. Low-SES students are those that live in strata 1 or 2 and all those that have the scholarship regardless of where they live (given that many come from outside the capital and may currently be living with a relative or in a students' residence - living in dorms is not the norm in this context). Middle-SES students are those that live in strata 3 or 4 and are not scholarship recipients. High-SES students are those that live in strata 5 or 6.

We analyzed SES segregation in three different ways: (1) examining friendship ties descriptively, (2) using the assortativity coefficient, and (3) through the implementation of a null analytical model to compare to results generated at random. The goal, like with all segregation measures, was to discover whether students with certain attributes, in this case of a specific SES, were to some degree connected to others with the same attributes more than to others with different attributes, i.e., presence of homophily by SES (Bojanowski \& Corten, 2014).

\section{Quantitative data analysis}

\section{Assortativity coefficient}

To test whether there were preferential ties related to the different attributes of the students in each network, particularly SES, we used the discrete assortative mixing coefficient $r$ proposed by Newman (2003). The $r$ index varies between -1 and 1 . A value of 1 means that individuals tend to relate with others with similar characteristics (assortativity), and -1 with different characteristics (disassortativity). A value of 0 indicates that there is no tendency towards assortative/disassortative relations in the network. This coefficient is estimated using Eq. (1) below.

$$
r=\frac{\sum_{i} e_{i i}-\sum_{i} a_{i} b_{i}}{1-\sum_{i} a_{i} b_{i}}
$$

where $e_{i i}$ is the fraction of ties that connects nodes of category $i$ to nodes of category $j$, $\sum_{i} e_{i i}$ represents the sum of the fraction of ties between the same category $i, \sum_{i} e_{i j}=a_{i}$ represents the sum of the fraction of ties that start in a node of category $i$ and target other categories $j$, and $\sum_{j} e_{j i}=a_{i}$ represents the fraction of ties that target a node of category $i$ and start in other categories $j$, and its multiplication is the fraction of ties that start AND target the category $i$; over the fraction of ties that are not starting nor targeting the same category $i$.

\section{Null model}

To test whether there were ties related to the SES groups of students, we implemented a mean degree constrained null model. This model has been largely used in network analyses to test the number of existing ties between classes compared to the possible existing ties if these were generated by random networks with similar characteristics and distribution of attributes (Montes et al., 2017; Newman \& Girvan, 2004). We compared the proportion of ties between and within the SES groups of our empirical networks with the proportions from networks with the same topological structure, size, and average connectivity of each SES group, and nodes randomly assigned to the SES categories following the 
original distribution. This null model allowed us greater control over the comparison sample and a more straightforward interpretation of the results than the well-known ERGMS. Odds ratios measure the probabilities of significant structures in random networks in the ERGMS. In contrast, null models measure whether the studied variables behave as is expected in random networks with the same topological and demographic structure or whether the variable is significantly higher or lower. As ERGMS, null models also account for the non-independence of links missing in Logit models (Koehly et al., 2004). We generate random networks to test whether the existing ties between each pair of SES groups (e.g., low-low, low-middle) were significantly less, more, or non-different than the simulated distribution if ties were generated by chance. The following procedure was used to perform the null model:

1. We calculated the proportion of nodes in each SES group (low, middle, high).

2. We calculated the number of ties between each pair of SES groups (e.g., low-low, low-middle).

3. We generated random networks with the same size (number of nodes), number of ties, and degree distribution.

4. To each node in the random network, we assigned an SES group at random, following the proportions of the original network calculated in step 1.

5. We repeated steps 2 to 4 until we reached a considerable number of random networks for statistical analysis. We only considered random networks with less than $10 \%$ difference in the total number of ties for each SES group compared to the original network.

6. We calculated the ratio of the number of ties of each pair of SES groups of the original observed network over that value in the random network.

7. We performed a two-sided test with a Fischer $p$-value for non-symmetrical distributions under the null hypothesis of no significant difference in relations between pairs of SES:

8. If $p$-value $<0.05$, then the number of ties between that pair of SES groups is significantly greater than expected by chance.

9. If $p$-value $>0.95$, then the number of ties between that pair of SES groups is significantly lower than expected by chance.

10. Otherwise, the number of ties between that pair of SES groups is not significantly different than expected by chance.

\section{Qualitative data collection}

We conducted a total of 61 in-depth interviews with undergraduate students on various programs, semesters, and SES (see Table 2). The average duration of the interviews was between 1 and $2 \mathrm{~h}$, but some were longer, extending for up to $4 \mathrm{~h}$. The students were asked about the socioeconomic situation of their families, their cultural capital and that of their families, ${ }^{4}$ previous educational experiences, how they decided what program and

\footnotetext{
4 To understand cultural capital, following Bourdieu (1984), we enquired into the formal education of parents and siblings as well what parents and students liked to do in their free time. Following Lareau (2011), we also asked questions about parenting styles in childhood (e.g., we would like to know a little about your past, when you were a child. What was your relationship with your parents like? Were they strict or relaxed? What did you do besides going to school? Did you play in the neighborhood, did you go to extracurricular activities, did you go to church?).
} 
Table 2 Qualitative interview participants' demographics
Interview respond-

ents

Sampling type

Nested in one of the surveyed programs 34

Ethnographic sample $\quad 27$

Total

Sex distribution

Male $\quad 38$

Female $\quad 23$

Total 61

Scholarship status distribution

Ser Pilo Paga scholarship holder $\quad 41$

Non-Ser Pilo Paga scholarship holder 20

Total 61

SES distribution

Low-SES $\quad 44$

Middle-SES 6

High-SES 11

Total 61

Institution

Study University $\quad 56$

Others $\quad 5$

Total

Program

Social sciences $\quad 11$

Psychology $\quad 7$

Medicine 16

Administration 5

Law $\quad 2$

Economics $\quad 14$

Engineering 5

Literature 1

Total $\quad 61$

Total $N$ of interviews

in what university to study, their positive and negative experiences in the university, their social capital before entering university and the networks they formed in college, ${ }^{5}$ their

\footnotetext{
5 To understand social capital and its changes, we asked who their best friends in high school were and what they were doing at time we interviewed them. We also asked about who their three best friends at university were and what they were like (Let's think about your three closest friends from college. Who are they, what do they do, and do they have any kind of scholarship? What do you do with them? Have you gone to his/her house? Has he/she been to yours?). We also asked about role models (people they admire and why) and about someone in the university they did not like and why (in an attempt to reveal symbolic boundaries and experiences of discrimination).
} 
perception of their peers (symbolic boundaries), life projects and experiences of injustice and discrimination. At the end of the interview, we explicitly asked them about their selfperception of class and cross-class relations at university.

In addition to the formal interviews, there were several informal conversations with these and other students who told us about their experience during their time at the university. Based on these conversations and several interactions that we observed on campus, we wrote field notes that we coded together with the interviews.

For the qualitative team, as a professor and students in the university we were studying, this project implied deep immersion, which brought great quality data and, at the same time, different ethical concerns, and care work beyond the strict research activities. Because of the practical implications of our research for the students' wellbeing, and the personal relationships we built with them, we were involved in different interventions throughout the project. We presented ongoing results to relevant authorities in the university, students (including some study participants), and the community in general, in an attempt to open up conversations and policies on diversity. We also helped students that needed different types of support, from counseling to collecting money to pay for tuition and connecting them with the university's psychological services.

We use pseudonyms for the participants in the study for narrative purposes, and in order to protect the participants' identities.

\section{Qualitative data analysis}

Interview and field notes transcriptions were analyzed in search of recurring themes associated to students' class experiences in college, using the N-Vivo software. Coding used both theoretical and inductive strategies to allow both the inclusion of themes that were related to prior literature (e.g., social capital and its sub-codes) and the emergence of new insights regarding the way class defines the college experience of working-class students (e.g., class and moral emotions such as shame and pride emerged as new codes during fieldwork). Cases, codebook, coding, and analysis were discussed and triangulated in weekly team meetings that helped with hypothesis building and the reliability of the findings. We then analyzed relations between codes, such as between socioeconomic status or family cultural capital and friendship experiences in the university.

Interviews were conducted in Spanish. The quotes presented here were translated by the main author.

\section{Results}

\section{Quantitative findings}

\section{General social integration of low-SES students}

The first aspect we analyzed was the existence of structural differences in the network positions of low-SES students versus their upper-class peers. We analyzed their centrality and isolation. We considered the number of classmates who nominated them as friends (indegree) and the number of classmates they nominated as friends (outdegree). On average, low-SES students were as central as other types of classmates, and in no way more isolated. Figure 1 illustrates these estimated results. 

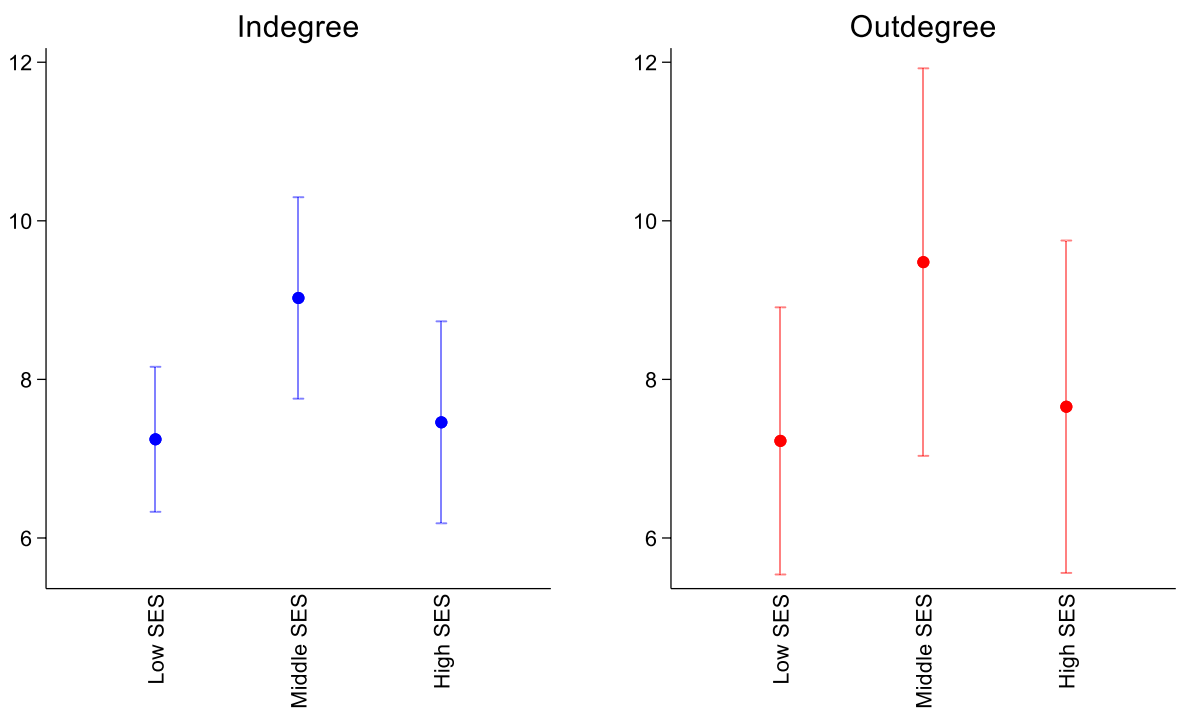

95\% Confidence Intervals

Fig. 1 Average number of incoming nominations as a friend (indegree) and outgoing nominations (outdegree) by SES

Low-SES students have a similar average number of friends as their other classmates (about 8). They are neither more "magnets" nor more "seekers" of friends in their university connections (Smith, 2015). Using these network measures, we can see that low-SES students are not less integrated into the university than their middle- or upper-SES classmates. We tested this with regression models of indegree and outdegree using SES as predictors controlling for program, sex, and GPA and found this result to be robust (detailed results are presented in the appendix).

\section{Cross-class social integration of low-SES students}

When we examined who the friends of the low-SES students are, we learned about more subtle differences in their social integration or segregation patterns. Figure 2 provides a descriptive illustration of this. Low-SES students nominate friends with a similar SES. Even if they have some friends in the upper SES, on average, they are the fewest (barely above one), followed by middle-SES friends, and more friends of their same SES.

Likewise, high-SES students nominate fewer low-SES students as their friends, but the difference is not statistically significant. Middle-SES students seem to be the brokers in these networks, connecting both with low and high-SES classmates. To further explore these differences in the SES of friends, including the brokerage role of the middle-SES students, we calculated the assortativity of the networks in general and compared this to the assortativity by removing the different SES nodes in different iterations (Table 3).

The assortativity coefficient varies between -1 and $1.1=$ complete assortativity (homophily). $-1=$ complete disassortativity. $0=$ random relations.

On average, friendship relationships appear not to be class homophilic in this university as assortativity by SES in general is low in all programs (assortativity by sex 


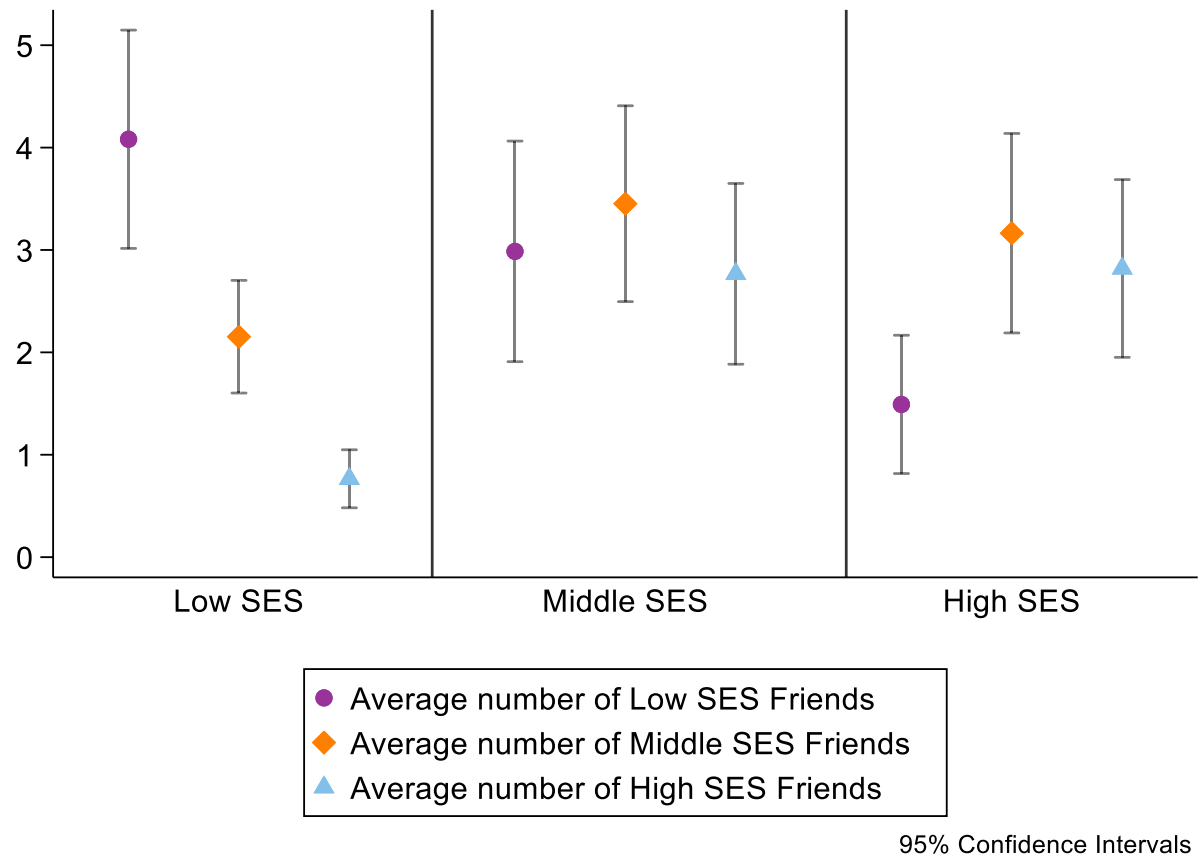

Fig. 2 Average number of different SES friends (outdegree) by student's SES

Table 3 Assortativity coefficients for the different program networks

\begin{tabular}{llllc}
\hline & Program 1 & Program 2 & Program 3 & Program 4 \\
\hline Sex & 0.23 & -0.01 & 0.01 & 0.04 \\
SES & 0.06 & 0.16 & 0.11 & -0.03 \\
SES (without low-SES students) & 0.00 & 0.10 & 0.04 & -0.07 \\
SES (without middle-SES students) & 0.41 & 0.27 & 0.33 & 0.05 \\
SES (without high-SES students) & 0.15 & 0.18 & 0.07 & -0.05 \\
\hline
\end{tabular}

is low as well, except for one of the programs in which assortativity increases to 0.23 ). However, the average assortativity increases greatly when we remove the middle-SES group of students, except in the least class-segregated program (program 4). This means that without the middle-SES students, friendship networks in this university become highly segregated, mostly because friendships between upper and lower-SES students are highly unlikely. This could be due to the higher number of nodes and ties among the middle-SES students.

To correct our analysis from the size bias of each SES category, we computed a null model to detect segregation among the different SES groups in our networks. This model makes it possible to distinguish between the segregation and integration of each SES group (Bojanowski \& Corten, 2014). Besides, if the segregation we see in the descriptive graphs holds up to this statistical test, we could analyze whether it occurs because the lower SES students nominate their upper-class classmates, the other way around, or both. 


\section{Null model}

According to the results (Table 4), low-SES to high-SES ties occur less frequently than expected by chance in three out of four of the programs we study. High to lowSES nominations are less expected than by chance in only one of these three programs Table 5.

In this table, nominations go from rows to columns. Each cell has the percentage of all nominations by the SES category on the left towards the SES category above. For any cell, negative signs (-) indicate that nominated relationships between the SES group in the row and the SES group in the column of that cell occur less than expected by chance. Similarly, positive signs $(+)$ mean that relationships between the SES group in the row and the SES group in the column of a cell, occur more than expected by chance. The model assigns $p$-values according to the inverse probability of the observed number of ties according to the distribution of randomly generated ties. For instance, a $p$-value smaller than 0.05 means that there is a less than $5 \%$ chance of obtaining the observed number of ties in the distribution of randomly generated ties. Here $p<0.1=*$ $p<0.05=* *$. Numbers accompanied by percentages in brackets in the columns' headlines are the size and the relative size of that group in each network.

According to these results, low-SES students tend to be homophilic in only one of these three programs, with more relations among themselves than with the other groups. The same happens with the high-SES students, again, in only one program. The observed relations between low and middle-SES are never significantly different than expected by chance.

In other words, relations in college for the low-SES students that we studied were not class homophilic. Yet, on average, relations with their higher SES peers were rarer than expected by chance. These results resonate with the qualitative findings. Different economic conditions, differences in cultural capital, and geographical differences make relationships between the most upper-class students and the low-SES students less likely.

\section{Qualitative findings}

Qualitative results shed light on the quantitative analysis, expanding and giving meaning to some of its results. They also reveal what remains hidden when we only ask about networks quantitatively. Thus, we learn from interviews and observations that the high level of social integration of the lower SES students that we see in the quantitative analysis comes with costs, the costs of social integration that are overwhelmingly on the shoulders of the less privileged students. Low-SES students have to devote a great amount of energy to their social integration into the university. These costs are much higher when becoming friends with upper-class classmates, and become smoother when becoming friends with lower- and middle-class friends.

\section{The hidden costs of cross-class friendships}

Given the elite status of Study University, we found that many scholarship recipients remember being overly conscious and even terrified during the first days of class. They feared having inadequate clothes, and, generally, being discriminated against for being 


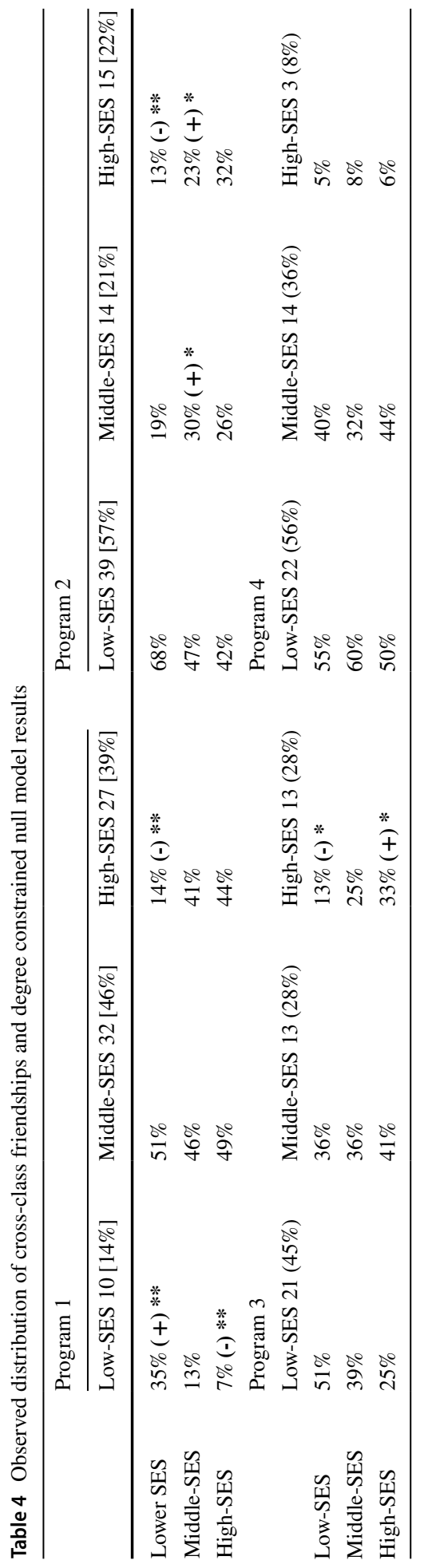


poor. They incurred in social, emotional, and economic costs in order to belong in the new environment. This is how a scholarship recipient on the university's law program remembers his first day:

I remember I felt terrible on induction day. I thought about what clothes I should wear, what if they laughed at my clothes? I was very conscious of this, and I spent most of the day on my own. I didn't want to talk to anyone, and I thought, "They might make fun of me or something." And that's how the day began, I had lunch, I had the refreshments they provided, and I went home, I didn't want to talk to anyone.

Camouflaging to fit in and belong was the strategy pursued by many low-SES students. "Passing" as non-scholarship students or just trying not to appear overtly different took a lot of effort for many of them, from learning and affording the dress codes, to understanding more subtle ways of "proper" behavior in class and outside. Feelings of inadequacy become less salient with time. Some learned to camouflage effectively. Some become more confident and even proud of their lower-class background.

Although fears of discrimination tended to fade with time and positive interactions, qualitative data also revealed experiences of micro-classism. Despite being rare, and often covert, these experiences are powerful in bringing the initial social anxiety back, and they can foster isolation among low-SES students. Tatiana, one of the most isolated students we interviewed, remembers a classmate asking her where she lived and that, when she answered she lived in Bosa - a heterogenous yet relatively poor area of the city - the classmate replied by saying "pobrecita" or "you poor thing."

\section{The possibilities of cross-class friendships}

Although we found isolated low-SES students in the interviews and qualitative fieldwork, and that this isolation had to do with feelings of class inadequacy like in the previous case, they were not the norm after the first semester. Most low-SES students had several friends on campus and some of them belonged to different social classes. Their integration may at least in part stem from the magnitude of the program. As we mentioned when we described the case, this program completely altered the socioeconomic composition of Study University, by bringing a much greater proportion of students from the lower classes. If a third of the incoming students were from the lower classes, the probability of meeting one of them and becoming friends with them was higher in terms of structural opportunities for interaction across social classes (Neal, 2010; Park et al., 2019). Although we have no measures of students' friendships before the program, our data shows some variation. We found that there was more low-class homophily in the program with the smaller proportion of lowSES students.

The selection mechanism used to grant certain students the scholarship - being low SES but also having exceptional academic abilities and being accepted to the university may also have helped social integration. This academic capital legitimizes their being in a college that holds high-quality standards and meritocracy as its main foundational principles. It empowers low-SES students and makes them feel entitled to be there. However, academic performance was also a source of feelings of inadequacy, given that many scholarship students felt, for the first time, that they had huge gaps from primary and secondary education compared to their classmates from higher social classes. As one low-SES student told us, "we have to accept it, scholarship students are not the people with the best GPAs. I mean, there is a huge difference between those who come from private schools and those 
of us who come from public schools. It's evident." Academic gaps are intensified by certain assumptions that, although slowly changing, were part of the hidden curriculum of this college when the scholarship started, for example, that all students could read in English, which was clearly not the case.

\section{Class variation in cross-class friendships}

In a context of previous educational and social segregation, we found that, generally, homophilic relations among low-SES students are just easier and provide greater possibilities for intimacy, for "being oneself". Practical reasons, such as taking the same bus back home, living close by in a huge and segregated metropolis such as Bogotá, or bringing lunch from home instead of spending money to buy it, are part of the story. But it is also about shared cultural capital. As Ana Sofía, a scholarship recipient student majoring in social sciences put it, when differentiating her middle-SES friend Camila from her low-SES friend Sergio:

I feel much more comfortable with Sergio than with Camila. I have been to Camila's house, I have stayed at her house, and we spent a lot of time together. But she talks about her trips. I never have lunch with her. With Camila everything is more academic, but we don't fool around. I always have lunch with Sergio; we worry about the same things, like where we are going to work when we finish college. And Sergio speaks like me. We laugh a lot.

Yet, this has not inhibited Ana Sofia, or other low-SES students, from making several middle-SES friends and, sometimes, some high-SES friends. Yet these friendships take much more relational work and rationalization (Álvarez-Rivadulla et al., 2021). In different conversations, Ana Sofía said that besides liking her upper SES friends, she knows it is good for her because she learns new things and has contacts.

Another student, now an upper-class young man in the health sciences, told us:

Yes, there is a distance. There are very practical things. My friends in the university from [his elite bilingual high school] like to go to El Corral [upscale burger chain] and get a 30.000 pesos burger for lunch [about 8 dollars at the time]. And for a person immersed in Colombia's social reality, that's simply not an option. So, often times, there are practical clashes.

Interestingly, this same student had a low-SES girlfriend, against his parents' will. She was very uncomfortable among his high-SES friends for more than practical reasons. She found that "the upper-class culture in Bogotá is hypocritical, superficial, and disrespectful." They lived in very socially distant neighborhoods of the city, so he never visited her while they were together. This upper-class student, however, has several low-SES friends. He thinks of himself as different from others in this regard.

We found that middle-SES students, in turn, face fewer difficulties in adapting upwards or downwards, economically and culturally. They are the most omnivorous. Many of them are the first generation in their families to go the university, and they are under different economic strains to pay for college. They share cultural capital and experiences with lowSES students, and they sometimes act as "cultural guides" (Corredor et al., 2019; Lareau, 2015) for them. When one student reflected upon the sometimes-bossy attitudes of one of her middle-SES friends, suggesting which dress to wear to her graduation party or how to properly order and eat at a restaurant, she recognized how much she had learned from her. 
Of course, this happens in an unequal context as it often does, in which learning how to behave in certain situations is more valued than knowing other types of cultural traits.

\section{Discussion and conclusion}

Based on their friendship networks and using a mixed methods perspective, this study investigates the integration of low-SES students in an elite university in the context of a very unequal country. Its results bring new dimensions to the literature on underprivileged students in elite colleges. In contrast to most prior findings (Rubin, 2012), we found that lower-class students can integrate via friendships even in an elite university and in an extremely unequal society. In Study University, low-SES students were, on average, no more isolated than upper-SES students; their networks were no more segregated; and they had the same number of connections. This is due to the mediating role of middle-class friends and the intense integration work burden that low-SES students have to assume in order to camouflage and fit in.

Our findings side with what Lee (2016) found in her ethnography of an elite university in the USA. It is not that elite-lower class relationships do not exist. Yet, these extreme cross class relations are difficult because they have to overcome economic and cultural capital differences (Bourdieu, 1998). They are either based on class silences and tensions or they take a lot of negotiation and relational work. The mixed-method nature of this project allowed us to see that behind the existing cross-class friendships that we measured and found quantitatively, laid a tremendous, invisible, and everyday effort to integrate that low-SES students engaged in, so as to fit into their new elite academic and social environment. Social integration has costs. And those costs are assumed rather invariably by the "outsiders".

Besides individual strategies, some college environments or government policies can foster those relationships both in terms of structural opportunities of interaction (Neal, 2010; Park et al., 2019) and college environment. The magnitude of the Ser Pilo Paga program and its focus on merit in an institutional environment with a strong competitive academic culture may have helped the general and cross-class integration of lower SES students, as did the availability of a great proportion of middle-class students. Their mediating role is both clear in the quantitative measures and in the qualitative evidence. Their role as "cultural guides" (Corredor et al., 2019; Lareau, 2015) becomes very important in low-SES students' integration.

Finding no general pattern of SES segregation is hopeful in terms of what education can do to generate social contact under certain conditions of relative equality (Allport, 1954), even in extremely unequal contexts. As stated elsewhere, class prejudices go in both directions (Álvarez Rivadulla, 2019). People that would have never met in such an unequal and segregated society as the Colombian one, met thanks to the Ser Pilo Paga program. This may have long lasting subjective and objective changes. However, from a social capital perspective (Granovetter, 1977; Lin, 2000), the lower likelihood of low-SES students becoming friends of high-SES students may limit the impact of these inter class interactions. This, in turn, may have future impacts on the labor market given that it is high-SES students that have the greatest access to better job opportunities.

Finally, the extra burden that low-SES individuals assume to integrate into elite education is worrisome and may affect students' psychological and academic outcomes. Although general environmental inequality is a difficult to change condition that fosters 
this burden, institutionally, it is important to attempt to reduce it. Exposing this burden is perhaps a first step that institutions facing similar challenges can take. Acknowledging and trying to detect class biases in teachers' expectations might be necessary as well. Detecting and trying to diminish academic gaps stemming from unequal educational trajectories is another crucial step. Talking about class inequalities within college, promoting uncomfortable conversations may be another one. Actively promoting safe spaces for lower class intergroup contact and mentorship and, at the same time, actively promoting inter class connections can be a route to promoting smoother integration processes. Overall, caring for diversity beyond enrollment (Hurtado et al., 1998; Park et al., 2019) seems to be the path we need to take to promote a better college environment for all.

\section{Appendix}

Table 5 Regression models for indegree and outdegree

\begin{tabular}{|c|c|c|c|c|}
\hline & (1) & (2) & (3) & \\
\hline & Indegree & Indegree & Outdegree & Outdegree \\
\hline Middle-SES & $\begin{array}{l}1.499 \\
(0.792)\end{array}$ & $\begin{array}{l}0.480 \\
(0.796)\end{array}$ & $\begin{array}{l}1.845 \\
(1.501)\end{array}$ & $\begin{array}{l}0.495 \\
(1.501)\end{array}$ \\
\hline High-SES & $\begin{array}{l}-0.394 \\
(0.820)\end{array}$ & $\begin{array}{l}-1.397 \\
(0.780)\end{array}$ & $\begin{array}{l}-0.473 \\
(1.396)\end{array}$ & $\begin{array}{l}-1.799 \\
(1.405)\end{array}$ \\
\hline Program 2 & $\begin{array}{l}-0.930 \\
(0.941)\end{array}$ & $\begin{array}{l}-0.358 \\
(0.897)\end{array}$ & $\begin{array}{l}-1.291 \\
(1.640)\end{array}$ & $\begin{array}{l}-0.534 \\
(1.594)\end{array}$ \\
\hline Program 3 & $\begin{array}{l}0.473 \\
(0.966)\end{array}$ & $\begin{array}{l}0.766 \\
(0.933)\end{array}$ & $\begin{array}{l}0.979 \\
(1.706)\end{array}$ & $\begin{array}{l}1.366 \\
(1.691)\end{array}$ \\
\hline Program 4 & $\begin{array}{l}-2.093^{*} \\
(0.910)\end{array}$ & $\begin{array}{l}-1.866^{*} \\
(0.923)\end{array}$ & $\begin{array}{l}-1.812 \\
(1.757)\end{array}$ & $\begin{array}{l}-1.511 \\
(1.764)\end{array}$ \\
\hline Female & $\begin{array}{l}-0.438 \\
(0.727)\end{array}$ & $\begin{array}{l}-0.930 \\
(0.720)\end{array}$ & $\begin{array}{l}-1.967 \\
(1.217)\end{array}$ & $\begin{array}{l}-2.618^{*} \\
(1.240)\end{array}$ \\
\hline $2018-2 G P A$ & & $\begin{array}{l}3.795^{* * *} \\
(0.662)\end{array}$ & & $\begin{array}{l}5.021^{* * *} \\
(1.253)\end{array}$ \\
\hline Constant & $\begin{array}{l}8.192^{* * *} \\
(0.913)\end{array}$ & $\begin{array}{l}-5.625^{*} \\
(2.535)\end{array}$ & $\begin{array}{l}8.810^{* * *} \\
(1.568)\end{array}$ & $\begin{array}{l}-9.472^{*} \\
(4.646)\end{array}$ \\
\hline$R$-squared & 0.030 & 0.124 & 0.005 & 0.053 \\
\hline Adj. $R$-squared & 0.055 & 0.151 & 0.031 & 0.082 \\
\hline$F$ & 2.496 & 7.519 & 0.958 & 3.039 \\
\hline Prob $>F$ & 0.023 & 0.000 & 0.454 & 0.005 \\
\hline$N$ & 232 & 232 & 232 & 232 \\
\hline
\end{tabular}

Standard errors in parentheses. ${ }^{*} p<0.05,{ }^{* *} p<0.01,{ }^{* * *} p<0.001$. 
Acknowledgements We are thankful for the contribution of Natalia Muñoz as an undergraduate research assistant for part of the analysis. Paola Camelo, Mariana Vargas, and Diana Viáfara were crucial for the qualitative fieldwork as research assistants. We are also thankful to the FAPA funding from Universidad de los Andes granted to professor Alvarez-Rivadulla.

\section{References}

AgurtoAdrianzén, M., Chevez, H. F., Morales, W. N., Quevedo, V., \& Chiyón, S. V. (2019). Study-group diversity and early college academic outcomes: Experimental evidence from a higher education inclusion program in Peru. Economics of Education Review, 72, 131-146.

Allport, G. W. (1954). The nature of prejudice. Addison.

Álvarez Rivadulla, M. J. (2019). ¿"Los becados con los becados y los ricos con los ricos"? Interacciones entre clases sociales distintas en una universidad de elite. Desacatos(59), 50-67.

Álvarez-Rivadulla, M. J. (2017). Ser Pilo Paga y la desigualdad en Colombia. (2017, 06/07/2017). Red de la Educación. La Silla Vacía.

Álvarez-Rivadulla, M. J., Camelo, P., Vargas-Serani, M., \& Viáfara, D. (2021). The relational costs of crossing class lines. Manuscript submitted for publication.

Aries, E. (2008). Race and class matters at an elite college: Temple University Press.

Aries, E., \& Seider, M. (2005). The interactive relationship between class identity and the college experience: The case of lower income students. Qualitative Sociology, 28(4), 419-443.

Bayon, C. (2015). La integración excluyente. Experiencias, discursos y representaciones de la pobreza urbana en México: Universidad Nacional Autónoma de México/Bonilla Artigas Editores, SA de CV.

Billingham, S. (2018). Access to success and social mobility through higher education: A curate's egg?: Emerald Group Publishing.

Bojanowski, M., \& Corten, R. (2014). Measuring segregation in social networks. Social Networks, 39, 14-32.

Bourdieu, P. (1984). Distinction: A social critique of the judgement of taste. Routledge.

Bourdieu, P. (1998). The state nobility: Elite schools in the field of power: Stanford University Press.

Corredor, J., Álvarez-Rivadulla, M. J., \& Maldonado-Carreño, C. (2019). Good will hunting: social integration of students receiving forgivable loans for college education in contexts of high inequality. Studies in Higher Education, 1-15.

Corredor, J., González-Arango, F., \& Maldonado-Carreño, C. (2020). When unintended effects are really unintended: depressive symptoms and other psychological effects of forgivable loan programs for college education. Higher Education, 1-18.

Creswell, J. W., \& Tashakkori, A. (2007). Differing perspectives on mixed methods research. Sage Publications Sage CA.

Ferreyra, M. M., Avitabile, C., Botero Álvarez, J., Haimovich Paz, F., \& Urzúa, S. (2017). At a crossroads: higher education in Latin America and the Caribbean: The World Bank.

García, S., Rodríguez, C., Sánchez, F., \& Bedoya, J. G. (2015). La lotería de la cuna: La movilidad social a través de la educación en los municipios de Colombia. Universidad de los Andes-CEDE.

García-Villegas, M., \& López, L. Q. (2011). Apartheid educativo. Educación, desigualdad e inmovilidad social en Bogotá. Revista de Economía Institucional, 13(25).

Gómez Campo, V. M., \& Celis Giraldo, J. E. (2009). Crédito educativo, acciones afirmativas y equidad social en la educación superior en Colombia. Revista de Estudios Sociales(33), 106-117.

González-Velosa, C., Rucci, G., Sarzosa, M., \& Urzúa, S. (2015). Returns to higher education in Chile and Colombia. IDB Working Paper Series.

Granovetter, M. S. (1977). The strength of weak ties. American Journal of Sociology, 78(6), 347-367.

Hurtado, S., Clayton-Pedersen, A. R., Allen, W. R., \& Milem, J. F. (1998). Enhancing campus climates for racial/ethnic diversity: Educational policy and practice. The Review of Higher Education, 21(3), 279-302.

Ingram, N. (2011). Within school and beyond the gate: The complexities of being educationally successful and working class. Sociology, 45(2), 287-302.

Jack, A. A. (2016a). (No) Harm in Asking Class, Acquired cultural capital, and academic engagement at an elite university. Sociology of Education, 89(1), 1-19.

Jack, A. A. (2016b). (No) harm in asking: Class, acquired cultural capital, and academic engagement at an elite university. Sociology of Education, 89(1), 1-19. 
Jack, A. A. (2019). The privileged poor: How elite colleges are failing disadvantaged students: Harvard University Press.

Koehly, L. M., Goodreau, S. M., \& Morris, M. (2004). Exponential family models for sampled and census network data. Sociological Methodology, 34(1), 241-270.

Lareau, A. (2011). Unequal childhoods: Class, race, and family life: Univ of California Press.

Lareau, A. (2015). Cultural knowledge and social inequality. American Sociological Review, 80(1), 1-27.

Lee, E. M. (2016). Class and campus life: Managing and experiencing inequality at an elite college: Cornell University Press.

Lee, E. M., \& Kramer, R. (2013). Out with the old, in with the new? Habitus and social mobility at selective colleges. Sociology of Education, 86(1), 18-35.

Lin, N. (2000). Inequality in social capital. Contemporary Sociology, 29(6), 785-795.

Londoño-Vélez, J., Rodríguez, C., \& Sánchez, F. (2020). Upstream and downstream impacts of college merit-based financial aid for low-income students: Ser Pilo Paga in Colombia. American Economic Journal: Economic Policy, 12(2), 193-227.

Marginson, S. (2016). The worldwide trend to high participation higher education: Dynamics of social stratification in inclusive systems. Higher Education, 72(4), 413-434.

McPherson, M., Smith-Lovin, L., \& Cook, J. M. (2001). Birds of a feather: Homophily in social networks. Annual Review of Sociology, 27(1), 415-444.

Medina, P., Ariza, N., Navas, P., Rojas, F., Parody, G., Valdivia, J. A., et al. (2018). An unintended effect of financing the university education of the most brilliant and poorest Colombian students: The case of the intervention of the Ser Pilo Paga program. Complexity, 2018.

Melo, L. A., Ramos, J. E., \& Hernández, P. O. (2014). La educación superior en Colombia: Situación actual y análisis de eficiencia. Borradores De Economía, 808(1), 2-9.

Montes, F., Jimenez, R. C., \& Onnela, J.-P. (2017). Connected but segregated: Social networks in rural villages. Journal of Complex Networks.

Neal, J. W. (2010). Hanging out: Features of urban children's peer social networks. Journal of Social and Personal Relationships, 27(7), 982-1000.

Newman, M. E. (2003). Mixing patterns in networks. Physical Review E, 67(2), 026126.

Newman, M. E. (2010). Newtworks: an introduction. : Oxford Press.

Newman, M. E., \& Girvan, M. (2004). Finding and evaluating community structure in networks. Physical Review E, 69(2), 026113.

Ostrove, J. M., \& Long, S. M. (2007). Social class and belonging: Implications for college adjustment. The Review of Higher Education, 30(4), 363-389.

Park, J., Bowman, N., Denson, N., \& Eagan, K. (2019). Race and class beyond enrollment: The link between socioeconomic diversity and cross-racial interaction. The Journal of Higher Education, 90(5), 665-689.

Park, J., Denson, N., \& Bowman, N. A. (2013). Does socioeconomic diversity make a difference? Examining the effects of racial and socioeconomic diversity on the campus climate for diversity. American Educational Research Journal, 50(3), 466-496.

Pettigrew, T. F., Tropp, L. R., Wagner, U., \& Christ, O. (2011). Recent advances in intergroup contact theory. International Journal of Intercultural Relations, 35(3), 271-280.

Rao, G. (2019). Familiarity does not breed contempt: Diversity, discrimination and generosity in Delhi schools. American Economic Review, 109(3), 774-809.

Reay, D., Crozier, G., \& Clayton, J. (2009). 'Strangers in paradise'? Working-Class Students in Elite Universities. Sociology, 43(6), 1103-1121.

Rios-Aguilar, C., Kiyama, J. M., Gravitt, M., \& Moll, L. C. (2011). Funds of knowledge for the poor and forms of capital for the rich? A capital approach to examining funds of knowledge. Theory and Research in Education, 9(2), 163-184.

Robbins, S. B., Lauver, K., Le, H., Davis, D., Langley, R., \& Carlstrom, A. (2004). Do psychosocial and study skill factors predict college outcomes? A Meta-Analysis. Psychological Bulletin, 130(2), 261.

Rubin, M. (2012). Social class differences in social integration among students in higher education: A metaanalysis and recommendations for future research. Journal of Diversity in Higher Education, 5(1), 22.

Rubin, M., Evans, O., \& Wilkinson, R. B. (2016). A longitudinal study of the relations among university students' subjective social status, social contact with university friends, and mental health and wellbeing. Journal of Social and Clinical Psychology, 35(9), 722-737.

Rubin, M., \& Wright, C. L. (2015). Age differences explain social class differences in students' friendship at university: Implications for transition and retention. Higher Education, 70(3), 427-439.

Smith, R. A. (2015). Magnets and seekers: A network perspective on academic integration inside two residential communities. The Journal of Higher Education, 86(6), 893-922. 
SNIES (2018). Sistema Nacional de Información de la Educación Superior (SNIES). . https://www.mined ucacion.gov.co/sistemasinfo/SNIES/.

Stephens, N. M., Fryberg, S. A., Markus, H. R., Johnson, C. S., \& Covarrubias, R. (2012). Unseen disadvantage: How American universities' focus on independence undermines the academic performance of first-generation college students. Journal of Personality and Social Psychology, 102(6), 1178.

Tashakkori, A., \& Teddlie, C. (2008). Foundations of mixed methods research: Integrating quantitative and qualitative techniques in the social and behavioral sciences. SAGE.

Telles, E. (2014). Pigmentocracies: Ethnicity, race, and color in Latin America: UNC Press Books.

Thomas, S. L. (2000). Ties that bind: A social network approach to understanding student integration and persistence. The Journal of Higher Education, 71(5), 591-615.

Torres, K., \& Massey, D. S. (2012). Fitting in: Segregation, social class, and the experiences of Black students at selective colleges and universities. Race and Social Problems, 4(3-4), 171-192.

Urrea, F., Viáfara, C., \& Viveros, M. (2014). From whitened miscegenation to tri-ethnic multiculturalism. Race and ethnicity in Colombia. Pigmentocracies. Ethnicity, Race, and Color in Latin America. The University of North Carolina Press, Chapel Hill, 81-125.

Viáfara López, C. A. (2017). Movilidad social intergeneracional de acuerdo al color de la piel en Colombia. sociedad y economía(33), 263-287.

Xie, A., \& Reay, D. (2019). Successful rural students in China's elite universities: Habitus transformation and inevitable hidden injuries? Higher Education, 1-16.

Publisher's Note Springer Nature remains neutral with regard to jurisdictional claims in published maps and institutional affiliations.

\section{Authors and Affiliations}

\section{María José Álvarez-Rivadulla ${ }^{1}$ Ana María Jaramillo ${ }^{2,3}$. Felipe Fajardo ${ }^{4}$ Laura Cely $^{1}$. Andrés Molano $^{5} \cdot$ Felipe Montes ${ }^{2}$}

Ana María Jaramillo

am.jaramillo37@uniandes.edu.co

Felipe Fajardo

f.fajardov@uniandes.edu.co

Laura Cely

lf.cely@uniandes.edu.co

Andrés Molano

a.molano@uniandes.edu.co

Felipe Montes

fel-mont@uniandes.edu.co

1 Facultad de Ciencias Sociales, Universidad de los Andes, Cra 1 № 18A- 12, Bogotá, Colombia

2 Facultad de Ingeniería, Universidad de los Andes, Bogotá, Colombia

3 Computer Science, University of Exeter, Exeter, England

4 Facultad de Economía, Universidad de los Andes, Bogotá, Colombia

5 Facultad de Educación, Universidad de los Andes, Bogotá, Colombia 